\title{
STRATEGI PEMASARAN JASA PENDIDIKAN DALAM MENINGKATKAN CITRA SEKOLAH DI SDN 2 ARGOMULYO DESA ARGOMULYO KECAMATAN SUMBEREJO KABUPATEN TANGGAMUS PROVINSI LAMPUNG
}

\author{
Mamlukah $^{1}$, Weni Wahidatun Nufusiah ${ }^{2}$ \\ e-mail: mamlukhah0876@gmail.com ${ }^{1}$, weniywahidatunnufusiah25@gmail.com ${ }^{2}$ \\ Prodi Manajemen Pendidikan Islam \\ Institut Agama Islam Darussalam Blokagung Banyuwangi
}

\begin{abstract}
Abstrak
Penelitian ini bertujuan untuk mengetahui strategi pemasaran jasa pendidikan di SDN 2 Desa Argomulyo Kecamatan Sumberejo Kabupaten Tanggamus Provinsi Lampung. Metode penelitian yang digunakan adalah deskriptif kualitatif, dengan pendekatan studi kasus. Mengenai prosedur pengumpulan data, dengan cara observasi, wawancara dan dokumentasi yang kemudian dilakukan uji keabsahan data, melalui uji credibility, transferability, dependability, dan confirmability. Alat analisis data yang digunakan menggunakan analisis IFAS, EFAS dan SWOT. Hasil penelitian menunjukkan strategi pemasaran jasa pendidikan yang digunakan oleh SDN 2 Argomulyo dalam memanfaatkan kekuatan atas peluang yang telah diidentifikasi: sekolah mengoptimalkan kinerja guru, menjaga nama baik sekolah, memperkuat nama baik sekolah dimasyarakat. Dalam meminimalkan kelemahan guna memanfaatkan peluang: meningkatkan frekuensi pelatihan, meningkatkan fasilitas yang berbasis teknologi. Dalam menggunakan kekuatan guna mengatasi ancaman: SDN 2 Argomulyo mengembangkan dan menyesuaikan model pemasaran dan menciptakan gaya ekstrakulikuler lebih menarik. Dalam meminimalkan kelemahan guna menghindari ancaman: mengadakan progam pelatihan guru, menyebarluaskan nama sekolah ketika terjun di lapangan dan mengoptimalkan pemasaran disemua media. Kesimpulan dari penelitian menunjukkan bahwa strategi pemasaran yang dilakukan sekolah kurang maksimal sehingga menyebabkan banyak kendala. Faktor utama adanya kendala pada pemasaran jasa pendidikan ini dikarenakan adanya sistim zonasi dan orang tua siswa lebih memilih menyekolahkan anaknya di sekolah yang lebih dekat dengan rumah.
\end{abstract}

Kata Kunci: Strategi Pemasaran Jasa Pendidikan, Citra Sekolah

Strategi Pemasaran Jasa Pendidikan dalam Meningkatkan Citra Sekolah di SDN 2 Argomulyo Desa Argomulyo Kecamatan Sumberejo Kabupaten Tanggamus Provinsi Lampung

Mamlukah, Weni Wahidatun Nufusiah 


\begin{abstract}
This study aims to determine the marketing strategy of educational services at SDN 2 Argomulyo Village, Sumberejo District, Tanggamus Regency, Lampung Province. The research method used is descriptive qualitative, with a case study approach. Regarding the data collection procedure, by means of observation, interviews and documentation, then the validity of the data is tested, through credibility, transferability, dependability, and confirmability tests. The data analysis tool used is IFAS, EFAS and SWOT analysis. The results show that the marketing strategy of educational services used by SDN 2 Argomulyo in exploiting the strengths of the opportunities that have been identified: the school optimizes teacher performance, maintains the good name of the school, strengthens the good name of the school in the community. In minimizing weaknesses to take marketing model and create a more attractive extracurricular style. In minimizing weaknesses in order to avoid threats: conducting teacher training programs, disseminating the name of the school when entering the field and optimizing marketing in all media. The conclusion of the study shows that the marketing strategy carried out by the school is not optimal, causing many obstacles. The main factor of the constraints on the marketing of educational services is due to the zoning system and parents prefer to send their children to schools that are closer to home.
\end{abstract}

Keywords: Education Service Marketing Strategy, School Image

\title{
A. Pendahuluan
}

Pertumbuhan pada masa globalisasi pada sekarang ini banyak pembangunan yang semakin berkembang, telah banyak pertumbuhan dan industri di Indonesia yang telahmengalamibanyak kemajuan yang sangat pesat dibandingkan dengan masa-masa sebelumnya. Dampaknyajuga dirasakan pada persaingan yang semakin tingggi pada semua aspek kehidupan masyarakat. Begitupun juga dengan pendidikan, dimana dalam mengelolanya tidak hanya digunakan cara tradisional akan tetapi membutuhkan kemampuan yang lebih baik sehingga output pendidikan sesuai dengan produk pasar yang dinginkan baik Nasional maupun Internasional.

Lembaga pendidikan juga ikut terpengaruh, apabila suatu lembaga tidak dapat mengelola manajemen bisnis dan manajemen pemasaran dengan tepat, maka nantinya akan mengalami kekalahan dalam bersaing dimana manajemen pemasaran merupakan salah satu kegiatan pokok yang dilakukan para pengelola pendidikan. Pengelolaan pendidikan menjadi begitu penting dimana pertumbuhan dan

Strategi Pemasaran Jasa Pendidikan dalam Meningkatkan Citra Sekolah di SDN 2 Argomulyo Desa Argomulyo Kecamatan Sumberejo Kabupaten Tanggamus Provinsi Lampung Mamlukah, Weni Wahidatun Nufusiah 
perkembangan lembaga pendidikan dipengaruhi oleh kemampuan administrator, dalam melakukan pertimbangan kompetensi internal dan harus dapat mengelola manajemen yang mumpuni agar dapat memenangkan persaingan sekolah sebagai produsen jasa pendidikan yang dapat menerima siswa dengan sangat mudah, calon siswa berlomba mendaftarkan diri masuk ke sekolah tanpa banyak persaingan dengan lembaga pendidikan yang lain. Tetapi, beberapa tahun terakhir ini beberapa lembaga jasa pendidikan mulai merasakan kesulitan terhadap mencari calon siswa. Anak-anak sekarang lebih cenderung memilih sekolah yang bermutu yang sesuai dengan yang diinginkan. Hal semacam ini juga diiringi dengan makin bertambahnya lembaga pendidikan jasa, misalnya saja jumlah madrasah.

Strategi pemasaran menjadi pijakan oleh lembaga pendidikan, tentunya harus menyesuaikan dengan perkembangan lingkungan. Potret atas tantangan lembaga pendidikan kedepan adalah adanya persaingan yang tinggi sehingga sangat banyak penawaran jasa lembaga pendidikan, meningkatnya tuntutan pelanggan atau siswa utamanya pada kualitas dan biaya, kemajuan teknologi komunikasi, informasi dan komputer yang merubah semua segi kehidupan dan sebagainya. Fungsi pemasaran adalah untuk membentuk citra yang baik terhadap lembaga dan menarik sejumlah calon siswa. Dengan demikian, citra merupakan salah satu upaya pemasaran pendidikan yang berdampak positif terhadap peningkatan minat pengguna jasa pendidikan yang berdampak positif terhadap peningkatan minat pengguna jasa pendidikan di lembaga pendidikan tersebut.

\section{B. Metode Penelitian}

PendekatandanjenisPenelitian ini mengangkat masalah strategi pemasaran pendidikan dalam meningkatkan citra sekolah di SDN 2 Argomulyo Desa Argomulyo Kecamatan Sumberejo Kabupaten Tanggamus Provinsi Lampung. Fokus penelitian ini menggunakan pendekatan kualitatif yang mengarah pada thick description (penjelasan panjang bebas dan holistik) peneliti ingin mengetahui, mempelajari dan

Strategi Pemasaran Jasa Pendidikan dalam Meningkatkan Citra Sekolah di SDN 2 Argomulyo Desa Argomulyo Kecamatan Sumberejo Kabupaten Tanggamus Provinsi Lampung 
memahami strategi pemasaran pendidikan dalam meningkatkan citra pada situs penelitian dengan menggunakan pendekatan studi kasus.

Menurut Sugiyono (2015:15) penelitian kualitatif adalah metode yang penelitiannya berlandaskan pada filsafat postpositive, yang mana hasil penelitian kualitatif lebih meneknkan pada makna dari pada generalisasi. Penelitian ini bertujuan untuk mendeskripsikan strategi pemasaran pendidikaan dalam meningkatkan citra, sehingga bagi peneliti dipandang perlu untuk mendalami makna strategi pemasaran pendidikan dalam meningkatkan citra sebagai sebuah fenomena.

Dipilihnya studi kasus dalam rancangan peneletian ini, karena peneliti ingin mempertahankan keutuhan subyek penelitian. Peneliti juga beranggapan bahwa fokus penelitian ini akan mudah dijawab dengan dessain/rancangan studi kasus.Didalam penelitian ini, peneliti berusaha untuk menggali data deskriptif selengkap mungkin yang berupa hasil wawancara nantinya, ataupun data-data tertulis yang mendukung kepentingan penelitian terutama yang terkait strategi pemasaran pendidikan dalam meningkatkan citra.Lokasipenelitianbertempat di SD 2 Argomulyo Desa Argomulyo Kecamatan Sumberejo Kabupaten Tanggamus Provinsi Lampung.

Dalam pengumpuan data ada beberapa teknik yang digunakan, menurut Yin (2008:103) pengumpulan data untuk studi kasus penelitian kualitatif berupa dokumen, rekaman arsip, wawancara, observasi dan perangkat fisik. Berikut penjelasan dari teknik pengumpulan data tersebut (Yin, 2013:117-118):

\section{Observasi}

Observasi atau pengamatan, yakni kegiatan memusatkan perhatian terhadap suatu yang diteliti denganmengamati serta mencatat secara sistematis hal-hal yang dianggap penting dan berkaitan dengan penelitian yang dilakukan dengan menggunakan panca indera. Menurut Sugiyono (2015:204) observasi merupakan kegiatan pemuatan penelitian terhadap suatu objek. Apabila dilihat pada proses pelaksanaan pengumpulan data, observasi dibedakan menjadi partisipan dan non-partisipan. Jenis observasi

Strategi Pemasaran Jasa Pendidikan dalam Meningkatkan Citra Sekolah di SDN 2 Argomulyo Desa Argomulyo Kecamatan Sumberejo Kabupaten Tanggamus Provinsi Lampung 
yang digunakan pada penelitian ini adalah observasi non-partisipan. Dalam melakukan observasi, peneliti memilih hal-hal yang diamati dan mencatat hal-hal yang berkaitan dengan strategi meningkatakan mutu pendidikan melalui program kelas.

2. Wawancara

Wawancara salah satu teknik guna mengumpulkan data apabila peneliti ingin melakukan studi pendahuluan untuk menemukan suatu permasalahan yang harus diteliti. Dokumentasi yang dimaksudkan adalah pengumpulan data yang bersifat dokumen yang terdapat pada lokasi penelitian, Menurut Moleong (2000:105) dokumen dapat digunakan sebagai sumber data dan dapat dimanfaatkan sebagai barang pembuktian, penafsiran dan pemaknaan suatu peristiwa.

3. Rekaman Arsip

Rekaman arsip seringkali dalam bentuk komputerisasi dan dalam bentuk lainnya. Kegunaan rekaman arsip akan bervariasi pada satu studi kasus dan lainnya. Pada beberapa penelitian rekaman tersebut begitu penting untuk analisis yang luas. Pada penelitian lainnya rekaman mungkin hanya sepintas relevansinya.

4. Perangkat Fisik

Perangkat fisik atau kultural yaitu peralatan teknologi, alat atau instrument, pekerjaan seni, atau beberapa bukti fisik lainnya. Perangkat semacam itu bisa dikumpulkan sebagai bagian dari kunjungan lapangan. Perangkat fisik mempunyai relevansi kurang potensial dalam studi kasus yang paling lazim. Namun demikian bilamana relevan perangkat tersebut bisa menjadi komponen penting dalam keseluruhan kasus yang bersangkutan.

Analisis data menurut Bogdan dalam bukunya Sugiyono (2013:244) adalah proses mencari dan menyusun, dilakukan dengan cara sistematis, dari hasil kegiatan

Strategi Pemasaran Jasa Pendidikan dalam Meningkatkan Citra Sekolah di SDN 2 Argomulyo Desa Argomulyo Kecamatan Sumberejo Kabupaten Tanggamus Provinsi Lampung 
wawancara, catatan lapangan, dan dokumentasi, kemudian dikelompokkan ke dalam kategori, menyusun ke dalam pola, memilih mana yang penting guna mendukung data pokok yang akan dipelajari, membuat penarikan kesimpulan sehingga data yang ada mudah difahami dan temuanya dapat diinformasikan kepada orang lain. Analisis data yang digunakan dalam penelitian ini, yaitu:

1. Analisis IFAS

Menurut Rangkuti (2002:24) analisis IFAS adalah kesimpulan analisis dari berbagai faktor internal yang mempengaruhi keberlangsungan lembaga pendidikan.

Tabel 2.1 Matriks IFAS (Internal Factors Analysis Summary)

\begin{tabular}{|c|c|}
\hline Faktor Internal & \multicolumn{1}{|c|}{ Keterangan } \\
\hline Strenghts $(S)$ & $\begin{array}{l}\text { Temuan data } \\
\text { kekuatanpadalembagapendidikan }\end{array}$ \\
\hline Weaknesses $(W)$ & $\begin{array}{c}\text { Temuan data } \\
\text { kelemahanpadalembagapendidikan }\end{array}$ \\
\hline
\end{tabular}

(Sumber: Rangkuti, 2002:24)

2. Analisis EFAS

Menurut Rangkuti (2002:26) adalah kesimpulan analisis dari berbagai faktor eksternal yang mempengaruhi keberlangsungan. Analisis EFAS digunakan untuk melihat peluang dan ancaman yang terdapat pada lembaga.

Tabel 2.2 Matriks IFAS (Internal Factors Analysis Summary)

\begin{tabular}{|c|c|}
\hline $\begin{array}{c}\text { Faktor } \\
\text { Internal }\end{array}$ & Keterangan \\
\hline Strenghts $(S)$ & $\begin{array}{l}\text { Temuan data } \\
\text { kekuatanpadalembagapendidikan }\end{array}$ \\
\hline $\begin{array}{c}\text { Weaknesses } \\
(W)\end{array}$ & Temuan data \\
kelemahanpadalembagapendidikan
\end{tabular}

Strategi Pemasaran Jasa Pendidikan dalam Meningkatkan Citra Sekolah di SDN 2 Argomulyo Desa Argomulyo Kecamatan Sumberejo Kabupaten Tanggamus Provinsi Lampung 
(Sumber: Rangkuti, 2002:24)

\section{Analisis SWOT}

Menurut Rangkuti (2009:18) analisis SWOT adalah suatu identifikasi mengenai faktor-faktor yang dilakukan secara sistematis guna merumuskan strategi yang ada pada perusahaan, guna mengetahui kekuatan, kelemahan, peluang dan ancaman yang ada pada SDN 2 Argomulyo di dalam memasarkan produk jasa pendidikan itu sendiri. Menurut Rangkuti (2014:83) matriks SWOT adalah alat yang dipakai untuk menyusun factor-faktor strategi perusahaan. Matrik ini dapat menggambarkan secara jelas bagaimana peluang dan ancaman yang dihadapi SDN 2 Argomulyo sehingga nantinya dapat disesuaikan dengan kekuatan dan kelemahan yang dimilikinya. Menurut Rangkuti (2009:21) matrik ini dapat menghasilkan empat kemungkinan alternatif strategi.

Tabel 2.3 Matriks SWOT

\begin{tabular}{|c|c|c|}
\hline IFAS & Kekuatan (Strenghts) & $\begin{array}{l}\text { Kelemahan } \\
\text { (Weaknesses) }\end{array}$ \\
\hline $\begin{array}{l}\text { Peluang } \\
\text { (Opportunities) }\end{array}$ & $\begin{array}{l}\text { Strategi } \\
\text { Memanfaatkan } \\
\text { kekuatan atas peluang } \\
\text { yang telah } \\
\text { diidentifikasi. }\end{array}$ & $\begin{array}{l}\text { Strategi W-O } \\
\text { memperbaiki atau } \\
\text { meminimalkan } \\
\text { kelemahan guna } \\
\text { memanfaatkan } \\
\text { peluang }\end{array}$ \\
\hline Ancaman (Threaths) & $\begin{array}{lr}\text { Strategi } & \text { S-T } \\
\text { Menciptakan strategi } \\
\text { yang menggunakan }\end{array}$ & $\begin{array}{lr}\text { Strategi } & \text { W-T } \\
\text { Menciptakan } & \\
\text { strategi } \quad \text { yang }\end{array}$ \\
\hline
\end{tabular}

Strategi Pemasaran Jasa Pendidikan dalam Meningkatkan Citra Sekolah di SDN 2 Argomulyo Desa Argomulyo Kecamatan Sumberejo Kabupaten Tanggamus Provinsi Lampung 


\begin{tabular}{|l|l|l|}
\hline & kekuatan guna & meminimalkan \\
mengatasi ancaman & kelemahan guna \\
& menghindari \\
& & ancaman \\
\hline
\end{tabular}

(Sumber data diolah, 2021)

Keterangan tabel :

1. Strategi S-O (Strenghts-Opportunities) Adapun kombinasi strategi yang dihasilkan adalah dengan memanfaatkan kekuatan atas peluang yang telah diidentifikasi.

2. Strategi W-O (Weaknesses- Opportunities) Adapun kombinasi strategi yang dihasilkan adalah memperbaiki atau meminimalkan kelemahan guna memanfaatkan peluang.

3. Strategi S-T (Strengths-Threaths) Adapun kombinasi strategi yang dihasilkan adalah menciptakan strategi yang menggunakan kekuatan guna mengatasi ancaman.

4. Strategi W-T (Weaknesses- Threaths) Adapun kombinasi strategi yang dihasilkan adalah menciptakan strategi yang meminimalkan kelemahan guna menghindari ancaman

\section{Hasil dan Pembahasan}

\section{Strategi Pemasaran Pendidikan}

Setiap pelaku usaha tentunya mempunyai tujuan dan cara tersendiri untuk kemajuan usahanya tersebut, baik itu dalam jangka pendek maupun jangka panjang. Untuk mencapai tujuan tersebut usaha atau bisnis perlu adanya rancangan dan tindakan untuk mencapai tujuan tersebut. Strategi atau rancangan antara pelaku usaha yang satu dengan yang lainya tentunya berbeda, selain itu setiap pelaku usaha juga mempunyai kebijakan tersendiri yang digunakan dalam menjalankan proses pemasaran.Menurut Buchari Alma

Strategi Pemasaran Jasa Pendidikan dalam Meningkatkan Citra Sekolah di SDN 2 Argomulyo Desa Argomulyo Kecamatan Sumberejo Kabupaten Tanggamus Provinsi Lampung 
(2005:176) dalam bukunya yang berjudul Kewirausahaan, Strategi adalah pola penentuan keputusan dalam perusahaan dengan menentukan sasaran, maksud atau tujuan yang menghasilkan kebijaksanaan utama serta merencanakan untuk mencapai tujuan secara terperinci dari jangkauan bisnis yang akan dicapai perusahaan. Dari pengertian diatas dapat diketahui bahwa strategi adalah suatu rencana yang akan dilakukan dalam usaha untuk mengahadapi persaingan.Kepala Sekolah SDN 2 Argomulyo melakukan kerjasama dengan masyarakat dan guru setempat beserta jajaran komite untuk meningkatkan daya saing dengan sekolah dalam meningkatkan citra lembaga.

Pemasaran merupakan salah satu kegiatan-kegiatan penting dalam usaha atau bisnis yang pokok dilakukan dalam usahanya untuk mengembangkan usaha atau bisnisnya, mempertahankan kelangsungan hidup usaha atau bisnis dan untuk mendapatkan keuntungan. Menurut American Marketing Association (AMA) (2004:214), pemasaran yaitu proses perencanaan dan pelaksanaan rencana penetapan harga, promosi dan distribusi dari ide-ide, barang-barang dan jasa-jasa untuk menciptakan pertukaran yang memuasakan dari tujuan individual dan organisasional.

\section{Bauran Pemasaran Jasa Pedidikan}

Menurut William J. Stanton yang dikutip Buchari Alma (2004:243), jasa adalah sesuatu yang dapat diidentifikasi secara terpisah dan tidak berwujud, di tawarkan untuk memenuhi kebutuhan. Jasa dapat dihasilkan menggunakan benda-benda berwujud atau tidak. Jadi jasa adalah setiap aktifitas dan manfaat yang ditawarkan oleh satu pihak kepada pihak lain, yang tanpa wujud tetapi dapat memberikan kepuasan bagi pembelinya. Sementara kualitas pelayanan dapat diketahui dengan cara membandingkan persepsi para konsumen atas pelayanan yang nyata-nyata mereka terima atau peroleh dengan pelayanan yang sesungguhnya mereka harapkan atau inginkan tarhadap atribut-atribut pelayanan satu organisasi lembaga pendidikan. Jika

Strategi Pemasaran Jasa Pendidikan dalam Meningkatkan Citra Sekolah di SDN 2 Argomulyo Desa Argomulyo Kecamatan Sumberejo Kabupaten Tanggamus Provinsi Lampung 
jasa yang diterima atau dirasakan sesuai yang diharapkan, maka kualitas pelayanan dipersepsikan baik dan memuaskan, jika jasa yang diterima melampaui harapan konsumen, maka kualitas pelayanan dipersepsikan sangat baik dan berkualitas. Sebaliknya jika jasa yang lebih rendah dari pada yang diharapkan, maka kualitas pelayanan dipersepsikan buruk.

Untuk keberhasilan sebuah lembaga dalam jangka panjang, maka lembaga tersebut harus menciptakan layanan yang memuaskan, 'need and want' pelanggannya. Guna menciptakan layanan yang memuaskan ini, maka lembaga menyiakan bauran pemasaran. Bauran pemasaran (marketing mix) merupakan unsur-unsur pemasaran yang saling terikat, dibaurkan, diorganisir, dan digunakan dengan tepat sehingga perusahaan dapat mencapai tujuan pemasaran dengan efektif, sekaligus memuaskan kebutuhan dan keinginan konsumen. Dalam dunia pemasaran jasa pendidikan juga tidak terlepas dari elemen bauran pemasaran. Adapun bauran pemasaran jasa yang dimaksud adalah konsep 7P, yaitu:

a. Konsepprince (harga) yang digunakan di SDN 2 Argomulyo

Mengenai harga yang digunakan di SDN 2 Argomulyo akan mempertimbangkan dan memperhatikan aspek nilai manfaat yang dapat diambil. Untuk menyikapi hal demikian maka lembaga mengadakan program yang berbeda setiap tahunnya, seperti pemberian barang setiap siswa mendaftar pada tiap tahunnya.Yang disesuaikan dengan program tahunan sekolah.

b. Konsep place (tempat) yang digunakan di SDN 2 Argomulyo

Pemilihan lokasi sekolah merupakan nilai penting yang harus dipertimbangkan oleh pihak lembaga di dalam mendukung pemasaran produk dan jasanya. Oleh sebab itu pihak lembaga harus menyusun strategi penempatan agar nantinya, anggota lebih mudah mendapatkan layanan produk yang ada di SDN 2 Argomulyo Strategi Pemasaran Jasa Pendidikan dalam Meningkatkan Citra Sekolah di SDN 2 Argomulyo Desa Argomulyo Kecamatan Sumberejo Kabupaten Tanggamus Provinsi Lampung 
Mengenai pemilihan lokasi yang digunakanyaitu: memilih lokasi atau lembaga yang lebih dekat dengan rumah.

c. Konsep promosion (promosi) yang digunakan di SDN 2 Argomulyo

Promosi dalam sekolah difungsikan guna media atau cara guna menyampaikan sebuah produk dan jasanya kepada pengguna layanan jasa pendidikan. Dalam hal ini lembaga harus mempunyai strategi agar penerima jasa layanan pendidikan mengenal serta tertarik untuk menyekolahkan anaknya di SDN 2 Argomulyo, dengan menggunakan produk dan jasa layanan yang ditawarkan. Mengenai model promosi yang digunakan di SDN 2 Argomulyo yaitu dengan cara membagikan brosur, pemeberitahuan secara aktif tentang sekolah dan pengenalan keterampilan sekolah.

d. Konsep people (orang) yang digunakan di SDN 2 Argomulyo

Guru guru yang ada di SDN 2 Argomulyo serta komite sekolah menjadi faktor penting yang menjadi pelaku nyata dalam menjalankan segala jenis kegiatan yang ada di dalam lembaga. Dalam peningkatan SDM yang perlu dilakuakan dengan sering diadakan pelatihan khusus. Kalau standar SDM yang bagus juga menghasilkan para pendidik yang baik.

e. Kendala yang ada pada proses pemasaran jasapendidikan di SDN 2 Argomulyo

Kendala yang ada pada lembagaini merupakan sebuah faktor penghambat yang menghalangi sebuah proses pencapain tujuan. Dalam hal ini pihak lembagaharus mengantisipasi dan meminimalisir sebuah kendala yang muncul pada pemasaran produk jasa pendidikan. Adanya sistim zonasi yang belum terealisasikan secara menyeluruh, terlebih orang tua lebih memilih menyekolahkan anaknya di sekolah yang dekat dengan rumah.

Strategi Pemasaran Jasa Pendidikan dalam Meningkatkan Citra Sekolah di SDN 2 Argomulyo Desa Argomulyo Kecamatan Sumberejo Kabupaten Tanggamus Provinsi Lampung 
f. Solusi SDN 2 Argomulyo guna mengatasi kendala pemasaran jasa pendidikan

Trobosan yang dilakukan lembaga merupakan sebuah usah atau antisipasi yang difungsikan guna mencari jalan keluar dari adanya kendala yang muncul dalam kegiatan pemasaran produk, sehingga tujuan daripada lembaga akan tetap tercapai.pihak SDN 2 Argomulyo harus terus menerus memberikan keyakinan kepada masyarakat sekitar dan wali murid, dalam pemasaran dianggap lebih mudah apabila menemukan wali murid yang sudah cukup faham mengenai jasa pendidikan yang ada di SDN 2 Argomulyo, maka usaha yang dilakukan tinggal meyakinkan.

\section{Penerapan Pemasaran Jasa Pendidikan di SDN 2 Argomulyo} Menggunakan Analisis SWOT

Setelah mengetahui faktor internal dan ekternal dari SDN 2 Arggomulyo, dilakukan penerapan menggunakan matriks SWOT, yang menghasilkan empat kemungkinan alternatif yang dimiliki oleh SDN 2 Argomulyo, yaitu:

1) Strategi S-O (Strenghts-Opportunities)

Memanfaatkan kekuatan atas peluang yang telah diidentifikasi :

a). Sekolah harus mengoptimalkan kinerja guru guna mengimbangi pertumbuhanpenduduk. Dengan mengoptimalkan SDM yang dimiliki sekolah, akan memberikan dampak pelayanan yang baik bagi wali murid dan masyarakat.

b). Menjaga nama baik sekolah guna menarik simpati calon siswa. Dengan menjaga nama baik sekolah akan memberikan nilai positif bagi masyarakat sehingga akan tertarik untuk menyeekolahkan anaknya di SDN 2 Argomulyo.

Strategi Pemasaran Jasa Pendidikan dalam Meningkatkan Citra Sekolah di SDN 2 Argomulyo Desa Argomulyo Kecamatan Sumberejo Kabupaten Tanggamus Provinsi Lampung 
c). Memperkuat nama baik sekolah dimasyarakat dengan memberikan informasi tentang pembaruan sekolah baik berupa prestasi atau estrakulikuler yang ada di sekolah. Hal ini akan berdampak pada nama baiksekolah.

d). Melakukan pendekatan langsung dengan masyarakat. Dengan dilakukannya pendekatan pada masyarakat desa sekitar, hal ini dianggap lebih mudah karena masih belum banyak dipengaruhi oleh skolah-sekolah yang berada diluar desa.

\section{2) Strategi W-O (Weaknesses- Opportunities)}

Meiminimalkan kelemahan guna memanfaatkan peluang:

a). Meningkatkan frekuensi pelatihan guna persediaan SDM. Dengan adanya pelatihan khusus dari pihak sekolah untuk semua guru, hal ini akan berdampak pada persediaan SDM dikemudian hari.

b). Meningkatkan fasilitas yang berbasis teknologi. Dengan peningkatan tekonologi yang dimiliki sekolah akan memberikan nilai yang unggul, guna bersaing dengan lembaga keuangan lain.

c). Terus aktif melakukan publikasi produk pada berbagai macam media. Dengan dilakukannya publikasi jasa pendidikan akan lebih mendukung pada nilai laku suatu jasa pendidikan yang ada di SDN 2 Argomulyo.

\section{3). Strategi S-T (Strengths-Threaths)}

Menciptakan strategi yang menggunakan kekuatan guna mengatasi ancaman:

a). Mengembangkan dan menyesuaikan model pemasaran jasa pendidikan. Dengan pengembangan dan penyesuaian strategi pemasaran yang dipakai, maka akan lebih mendukung guna memaksimalkan proses pemasaran jasa pendidikan.

Strategi Pemasaran Jasa Pendidikan dalam Meningkatkan Citra Sekolah di SDN 2 Argomulyo Desa Argomulyo Kecamatan Sumberejo Kabupaten Tanggamus Provinsi Lampung 
b). Menciptkan variasi produk yang lebih menarik. Dengan penciptaan variasi produk yang lebih menarik, akan lebih mendukung produk tersebut untuk dipilih.

c). Mempertahankan ciri khas produk sekolah. Dengan mempertahakan ciri khas sekolah, berdampak pada nama baik lembaga.

4) Strategi W-T (Weaknesses- Threaths)

Meminimalkan kelemahan guna menghindari ancaman :

a). Mengadakan progam pelatihan guna meningkatkan kopetensi guru. Dengan terus menerus dilakukannya pelatihan, maka akan meningkatkan SDM karyawan sehingga oprasional yang ada di sekolah akan lebih maksimal.

b). Menyebarluaskan nama sekolah ketika terjun di lapangan. Dengan menyebar luaskan nama sekolah, akan berdampak pada nama baik lembaga.

c). Mengoptimalkan pemasaran disemua media. Dengan mengoptimalkan pemasaran pada semua media akan mendukung pemasaran jasa pendidikan untuk mudah dikenal oleh masyarakat.

\section{Kesimpulan}

Dalam upaya meningkatkan eksistensi dan citra sebuah lembaga pendidikan, pengelola lembaga pendidikan dapat menerapkan konsep strategi pemasaran jasa pendidikan. Berdasarkan pembahasan penelitian maka dapat disimpulkan beberapa hal penting, yang pertama layanan jasa pendidikan di SDN 2 Argomulyo memprioritaskan pada upaya memenuhi harapan dan kepuuasan pelanggan indikaatornya adalah sebagai berikut: 1) Strategi S-O (Strenghts-Opportunities) dalam memanfaatkan kekuatan atas peluang yang telah diidentifikasi: sekolah mengoptimalkan kinerja guru guna mengibangi jumlah penduduk yang selalu

Strategi Pemasaran Jasa Pendidikan dalam Meningkatkan Citra Sekolah di SDN 2 Argomulyo Desa Argomulyo Kecamatan Sumberejo Kabupaten Tanggamus Provinsi Lampung 
bertambah, menjaga nama baik sekolah guna menarik simpati calon siswa, memperkuat nama baik sekolah dimasyarakat dengan melakukan pendekatan langsung dengan masyarakat melalui pemberitahuan aktif tentang perkembangan sekolah. 2) Strategi W-O (Weaknesses- Opportunities) dalam meminimalkan kelemahan guna memanfaatkan peluang: sekolah meningkatkan frekuensi pelatihan guna persediaan SDM, meningkatkan fasilitas yang berbasis teknologi dan terus aktif melakukan publikasi produk pada berbagai macam media. 3) Strategi S-T (StrengthsThreaths) dalam menggunakan kekuatan guna mengatasi ancaman: sekolah mengembangkan dan menyesuaikan model pemasaran, menciptkan gaya variasi jasa pendidikan yang lebih menarik dan mempertahankan ciri khas sekolah. 4) Strategi W$\mathrm{T}$ (Weaknesses- Threaths) dalam meminimalkan kelemahan guna menghindari ancaman: sekolah mengadakan progam pelatihan guna meningkatkan kopetensi guru, menyebarluaskan nama sekolah ketika terjun di lapangan dan mengoptimalkan pemasaran disemua media.

\section{E. Daftar Pustaka}

Al-Qur'anul Karim, Kemenag RI. 2014. Al Quddus. Depok: Arya Duta

Alma, Buchari. 2005. Manajemen Pemasaran Dan Pemasaran Jasa. Bandung: Alfabeta

Fradito, Aditya. 2020. Strategi pemasaran pendidikan dalam meningkatkan citra sekolah. Al-Idarah: Jurnal Kependidikan Islam 10 (1) 13:22

Moelong, Lexy J. 2000. Metodologi Penelitian Kualitatif. Bandung: PT. Remaja Rosdakarya

Rangkuti, Freddy. 2002. The Power Of Brans, Teknik Mengelola Brand Eguity Dan Strategi Pengembangan Merek. Jakarta: Gramedia Pustaka

Rangkuti, Freddy. 2009. Strategi Promosi Yang Kreatif Dan Analisis Kasus Integrated Marketing Communication. Jakarta: PT. Gramedia Pustaka Utama

Rangkuti, Freddy. 2014. Analisis SWOT Teknik Membedah Kasus Bisnis. Jakatra: PT. Gramedia Pustaka Utama

Strategi Pemasaran Jasa Pendidikan dalam Meningkatkan Citra Sekolah di SDN 2 Argomulyo Desa Argomulyo Kecamatan Sumberejo Kabupaten Tanggamus Provinsi Lampung

Mamlukah, Weni Wahidatun Nufusiah 
Vol. 3, No. 1: 1-16, April 2021

ISSN: 2722-7146 (Media Online)

Rangkuti, Freddy. 2009. Strategi Promosi Yang Kreatif Dan Analisis Kasus Integrated Marketing Communication. Jakarta: PT. Gramedia Pustaka Utama

Sugiyono. 2013. Metode Penelitian Kuantitatif, Kualitatif Dan R\&D. Bandung: Alfabeta

Sugiyono. 2015. Metode Penelitian Kuantitatif, Kualitatif Dan R\&D. Bandung: Alfabeta

Yin, Robert K. 2014. Studi Kasus Desain Dan Metode. Jakarta: Rajawali Pers

Strategi Pemasaran Jasa Pendidikan dalam Meningkatkan Citra Sekolah di SDN 2 Argomulyo Desa Argomulyo Kecamatan Sumberejo Kabupaten Tanggamus Provinsi Lampung

Mamlukah, Weni Wahidatun Nufusiah 